\title{
Resting and Dynamic Electrocardiography in Dogs with Experimental Chagas Cardiomyopathy
}

\author{
R. Oliveira Alves, ${ }^{1}$ A. A. Camacho, ${ }^{2}$ and D. P. Junior ${ }^{2}$ \\ ${ }^{1}$ Departamento de Medicina Veterinária, Universidade Federal de Goiás, Goiânia, GO, Brazil \\ ${ }^{2}$ Departamento de Medicina e Cirurgia Veterinárias, UNESP, Jaboticabal, SP, Brazil
}

Correspondence should be addressed to R. Oliveira Alves, rosangela2210@gmail.com

Received 21 March 2012; Revised 8 May 2012; Accepted 10 May 2012

Academic Editor: Alfonso J. Rodriguez-Morales

Copyright ( $) 2012$ R. Oliveira Alves et al. This is an open access article distributed under the Creative Commons Attribution License, which permits unrestricted use, distribution, and reproduction in any medium, provided the original work is properly cited.

\begin{abstract}
In the present protocol, adult dogs were infected with Trypanosoma cruzi, Bolivian strain, in order to show electrocardiographic changes by means of resting and dynamic (Holter) methods during acute and chronic phases of Chagas disease. In the acute phase there were sinus tachycardia, atrial and left ventricular overload, millivoltage suppression, electric alternance, and episodes of sinus arrest. At the parasitemia peak, atrium-ventricular block, junctional escape complexes, and atrium-ventricular dissociation were observed. Dogs that presented the most serious arrhythmias died suddenly. The increase in supraventricular and ventricular arrhythmic events, concentrated in the 4 th postinoculation week, was visible at electrocardiographic monitoring. In the chronic phase, the events were restricted to first-degree atrium-ventricular blocks, premature ventricular complexes, ventricular bigeminy, and electrical alternation. It was concluded that the computerized and dynamic electrocardiography allowed to diagnose transient arrhythmia and to observe that the main tachyarrhythmic changes are concentrated at the acute phase concomitantly to the parasitemia peak.
\end{abstract}

\section{Introduction}

Even a century after its discovery, Chagas disease remains a significant public health problem whose pathogenesis is not well understood, which perpetuates it as an intriguing challenge arising from the complex host-parasite interaction. It is an American exclusive endemic disease, which goes from the southern United States to southern Argentina, and it represents a major cause of morbidity and mortality in Latin America [1]. Currently, 10 million people living between Mexico and Argentina are infected, 10.000 people died only in 2008 as a result of this disease, and it is estimated that 28 million people are at high risk of acquiring it [2].

Dogs have been considered an important domestic reservoir of the parasite and also serve as a sentinel to detect infection in humans [3], requiring more attention by the scientific community [4]. Moreover, it is considered a suitable experimental model to the study of Chagas disease, because it is the only one so far to develop all phases of the disease, and showing similar manifestations as in humans.
Considering this scenario, in the present protocol, adult dogs were infected with Trypanosoma cruzi, Bolivian strain, with the purpose of showing the electrocardiographic changes produced by this strain during the acute and chronic phases of the disease and, thus, providing more accurate and enlightening data about this disease.

\section{Materials and Methods}

The experimental activities were carried out in the Laboratories of Cardiology, Pathology and Immunoparasitology of the College of Agriculture and Veterinary Sciences (FCAV), Universidade Estadual Paulista_-UNESP (Paulista State University).

The olivian strain of $T$. cruzi used in this study was isolated from a human clinical case in Bolivia and maintained in BALB/C albino mice. After acquiring the mice and determining the parasitemia, the inoculum for experimental infection of dogs was made. 
In order to standardize the inoculum, 6000 trypomastigotes $/ \mathrm{kg}$ were used. The counting of the number of trypomastigotes was made according to the technique described by Brener [5]. The route used for the inoculum administration was intravenous (IV).

Sixteen adult mixed breed dogs, seven males and nine females, were used. The animals came from the municipal kennels of the towns neighboring Jaboticabal, State of São Paulo, Brazil. The dogs were initially dewormed and vaccinated; they also received balanced diet and water adlibitum.

Before inoculation, the animals were submitted to physical examination, indirect immunofluorescence test for detection of anti-T. cruzi, hematological tests, serum chemistry, ECG, and echocardiogram in order to certify their healthiness.

After inoculation of T. cruzi, the same parameters previously mentioned were assessed weekly, for five consecutive weeks, in the animals, which were distributed in Acute Chagasic Group (CA, $n=8$ ) and Acute Control Group (C1, $n=8$ ) and, monthly, for six consecutive months, in Chronic Chagasic Group (CC, $n=8$ ) and Chronic Control Group $(\mathrm{C} 2, n=8)$.

To determine the parasitemia curve in infected dogs during the acute phase of infection, blood samples were collected and evaluated from the 4 th day of postinoculation on. Set the prepatent period, monitoring of parasitemia was performed from the 13th to 35 th day after infection, with intervals of three days, according to the technique by Brener [5], continuing until the complete disappearance of trypomastigotes in the evaluated samples.

Sera from all animals before inoculation were submitted to indirect immunofluorescence test weekly until 5 weeks and monthly until 6 months after inoculation, from 1: 40 dilution on. The antigen substrates prepared with epimastigotes of T. cruzi, Y strain [6], were provided by the Department of Parasitology, Microbiology and Immunology, Faculty of Medicine of Ribeirão Preto, State of São Paulo, Brazil (FMRP-USP).

The tracings obtained from the resting ECG were recorded in the following leads: bipolar leads (I, II, III); unipolar leads (aVR, aVL, and aVF); precordial leads (V4), through computerized electrocardiograph (ECG-PC, Tecnologia Eletrônica Brasileira, TEB) in $50 \mathrm{~mm} / \mathrm{seg}$ speed and calibrated to one millivolt equal one centimeter [7]. The records were stored in computer. The tracings were analyzed in derivation II, in which the $\mathrm{P}, \mathrm{R}$, and $\mathrm{T}$ waves amplitudes were measured (in $\mathrm{mV}$ ), durations (in $\mathrm{ms}$ ) of $\mathrm{P}$ wave, QRS complex, PR and QT intervals, and the frontal electrical axis, determined in derivations I and III, according to Tilley [7] and Wolf et al. [8].

The dynamic electrocardiography (Holter system) was performed by means of the "Holter" ECG device (SPACE LABs-MODEL 90205) in two precordial leads (rV2 and V4) for 24 hours on a weekly and monthly basis for groups CA and $\mathrm{C} 1$ and groups $\mathrm{CC}$ and $\mathrm{C} 2$, respectively.

The electrocardiograph was placed in a light and comfortable leather vest, allowing the animals to move freely and aiming at protecting the wires attached to the adhesive electrodes. The device was attached to the wires and the time

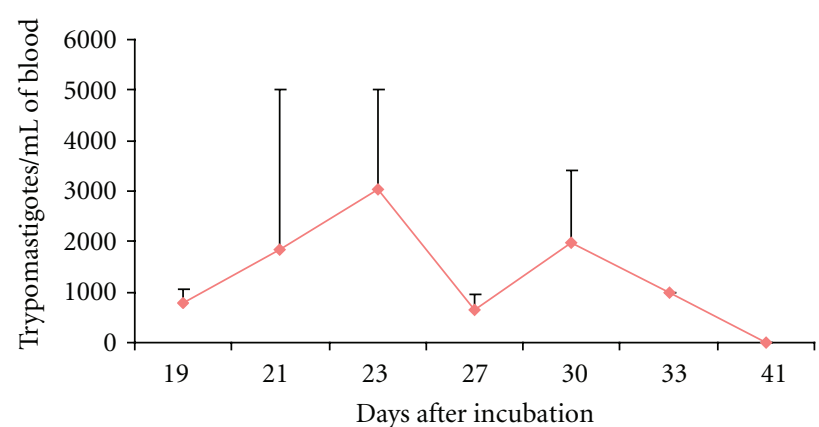

Figure 1: Graphic representation of the mean values of trypomastigotes/mL of blood in dogs experimentally inoculated with Trypanosoma cruzi during the acute phase of the infection. UNESP, Jaboticabal, SP, 2003.

was set (time zero). It was turned off at the end of 24 hours. The tapes were analyzed by the Holter ECG Interpretation Service of the Institute of Cardiovascular Diseases in São Jose do Rio Preto, State of São Paulo, Brazil, through computer decoding.

The data were analyzed using analysis of variance and the Tukey test to compare means among groups and weeks within the same group. The variables concerning the examination of dynamic electrocardiography were evaluated by nonparametric Wilcoxon method $[9,10]$.

\section{Results}

It was possible to verify that the parasitemia period of Bolivian strain in dogs inoculated with 6000 trypomastigotes $/ \mathrm{kg}$ occurred from the 19th to the 33rd post-incubation days (Figure 1).

The resting electrocardiography showed a significant increase of the cardiac frequency between the 2nd and 5th weeks after inoculation. The duration of $\mathrm{P}$ wave and QRS complex was above the normal values for the species between the 4 th and 5 th weeks, suggesting the presence of atrium and left ventriculum overload. During the last two weeks, the presence of decreased R-wave amplitude was also observed in $50 \%$ of the animals in Group CA. Electric alternance was verified in $10 \%$ of the dogs in the 3rd week and also abrupt significant cardiac axis deviation to the left in 4 th and 5th weeks (Figure 2).

As for the cardiac rhythm, sinus rhythm was observed in $100 \%$ of the dogs in the first week, and episodes of sinus arrest were verified in $16.7 \%$ of the animals. In the second week, $50 \%$ of the animals presented sinus rhythm, $33.33 \%$ had respiratory sinus arrhythmia, and $16.67 \%$ started presenting signs of sinus tachycardia.

Approaching the parasitemic peak ( 3 rd week), arrhythmias became more frequent, and $40 \%$ of the dogs showed sinusal rhythm, 30\% respiratory sinus arrhythmia, 20\% sinus tachycardia, $10 \%$ atrium-ventricular block, $10 \%$ junctional scape complexes, $10 \%$ third-degree atrioventricular block. From this week on, the dogs $(n=4)$ whose electrocardiograms presented the most arrhythmias died suddenly. 


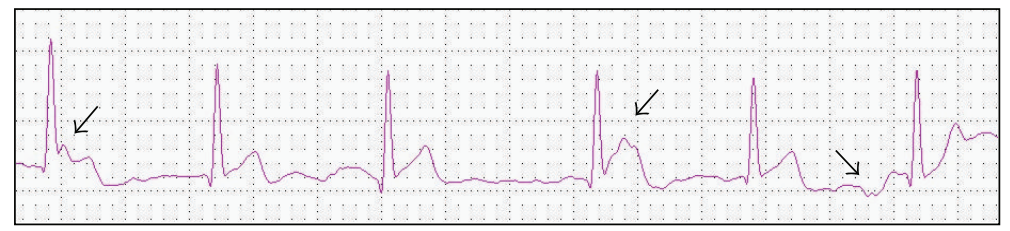

(a)

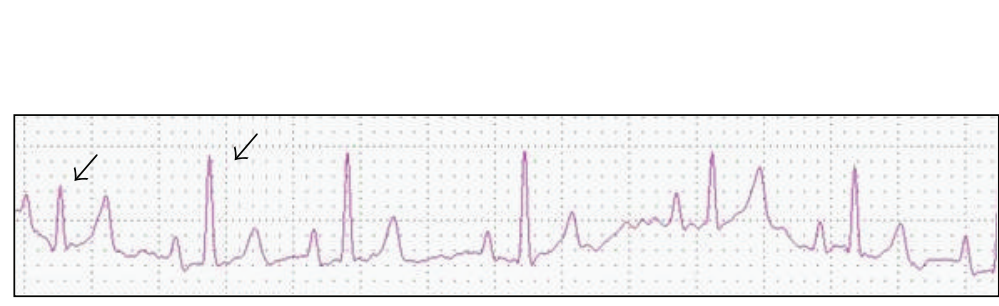

(b)

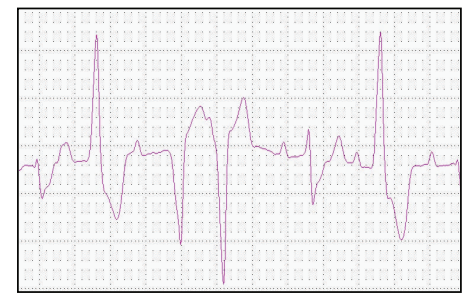

(d)

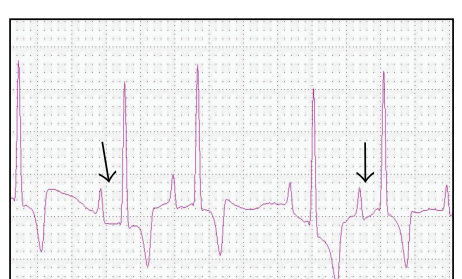

(e)

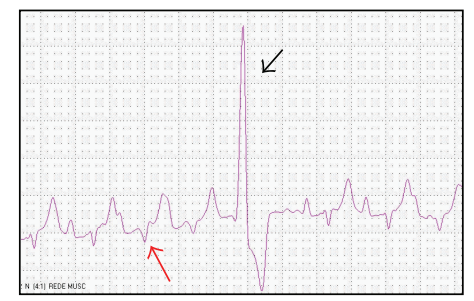

(c)

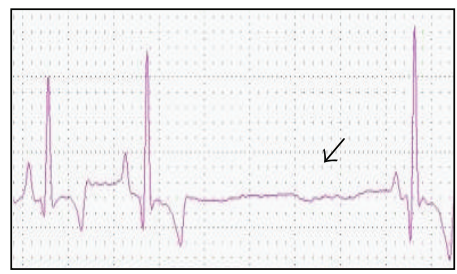

(f)

FIGURE 2: Resting electrocardiographic tracings obtained from dogs of the Acute Chagasic Group (speed $25 \mathrm{~mm} / \mathrm{s}$ ). (a) Derivation II, presenting third-degree atrioventricular block (arrows); (b) Derivation II, showing electric alternance of QRS complexes (arrows); (c) derivation II, showing decrease of R-wave amplitude, right branch block (red arrow) and ventricular extrasystole (black arrow); (d) derivation $\mathrm{V}_{4}$, showing premature isolated and paired multifocal ventricular complexes; (e) derivation II, showing first-degree atrioventricular block (arrows); (f) derivation II, showing sinusal rhythm with sinus arrest (arrow). UNESP, Jaboticabal, SP, 2003.

In the 4 th week, $50 \%$ of the dogs presented sinus rhythm and $50 \%$ had sinus tachycardia, and of these, $50 \%$ presented premature ventricular complexes. In the last week of the acute period, $50 \%$ of the dogs presented sinus rhythm, $25 \%$ respiratory sinus arrhythmia, and 25\% sinus tachycardia, and of these $25 \%$ presented first-degree atrium-ventricular block and $25 \%$ premature ventricular complexes.

The electrocardiogram of Group C1 did not present any alteration and sinus rhythm and respiratory sinus arrhythmia with the presence of migratory pacemaker were observed in weekly varying frequency.

Dynamic electrocardiography (Holter system) did not present statistical significance due to great individual variation. However, the increase of the number of QRS complexes evaluated during the 24-hour period from the second week on, reflecting tachycardia, as well as a visible increase of ventricular and supraventricular arrhythmia events, concentrated in the 4th week after the inoculation, could be observed.

Regarding minimum, medium, and maximum cardiac frequencies, Group CA always presented higher values than Group C1, although there were no significant differences. As for the number of pause, Group CA presented lower numbers than Group C1 from the second week on.

One of the dogs from the Acute Chagasic Group presented sudden death during Holter evaluation after the

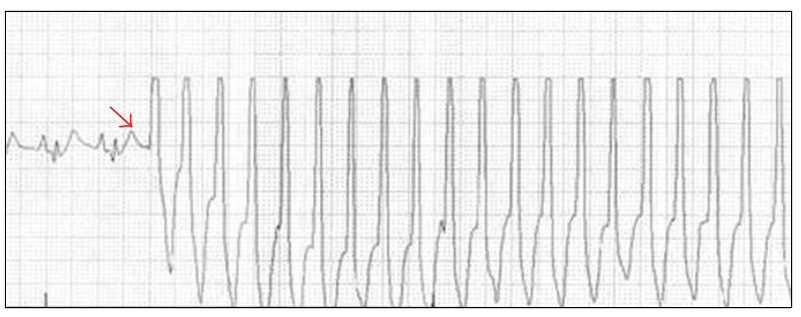

FIGURE 3: Dynamic electrocardiography tracing of one dog from the Acute Chagasic Group showing the presence of $\mathrm{R}$ in $\mathrm{T}$ phenomenon, trigger of sustained ventricular tachycardia which led to the animals sudden death. UNESP, Jaboticabal, SP, 2003.

occurrence of the R-on-T phenomenon triggering the episode of sustained ventricular tachycardia and ventricular fibrillation (Figure 3).

At 41 days after the inoculation, the dogs no longer presented parasitemia, thus, they were classified in the undetermined chronic phase of Chagas disease. During the sixmonth period of evaluation, computerized electrocardiogram did not present many alterations regarding the measurable values. A significant shortening of the PR interval was observed in the 6th month, and the amplitude of $\mathrm{R}$ wave in Group CC remained significantly lower than in Group C2. 
The events were limited to first-degree atrium-ventricular blocks, premature ventricular complexes, ventricular bigeminy, and electric alternace. At the end of the sixth month there were no more arrhythmia episodes and all the dogs presented sinus rhythm.

Dynamic electrocardiography showed gradative reduction of most arrhythmia events in Group CC, and some of them, such as supraventricular ectopic beat, isolated supraventricular arrhythmias, paired supraventricular arrhythmias, and supraventricular arrhythmias, have not occurred since the beginning of the undetermined chronic phase. Other events reached null value until the sixth month, such as isolated, bigeminy and paired ventricular arrhythmias, and ventricular tachycardia. The minimum, medium, and maximum frequencies did not present alterations and the number of pauses increased clearly, especially in the third month, as tachycardia became infrequent.

Serology, carried out by means of indirect immunoflourescence method, showed titers increase until the fourth month in two dogs, while the others stabilized their titration. There was a small mild titer increase in two dogs in the fifth month and negative result to the 1: 80 dilution in animals of the group in the sixth month. Such data do no mean, however, that the animals were free of trypanosomiasis, but probably the number of antibodies was temporarily undetectable by this technique.

\section{Discussion}

The parasitemic period observed from the 19th to the 33rd days after inoculation with parasitemia peaks in the $3 \mathrm{rd}$ and 4th weeks differed slightly from the one found by Klein [11], who verified that on the 16th day all the animals were in parasitemia and on the 31st day there were no more signs of trypomastigotes in the blood, as well as from the results by Barr et al. [12] who observed parasitemic period in inoculated dogs from the 18th to the 31st days after experimental inoculation.

Penin et al. [13], working with mice infected by the Bolivian strain, observed that the beginning of the parasitemic period occurred on the seventh day after inoculation, and Lopes et al. [14] observed it on the ninth day after inoculation. These data allow the inference that the Bolivian strain presents a later and longer parasitemic period regarding the experimental infection of the canine species.

The resting electrocardiographic exam was extremely efficient to identify the arrhythmic alterations in the acute phase of Chagas disease. The alterations suggestive of atrium and left ventriculum overload were similar to the ones described by Pinto et al. [15] in humans in the acute phase of the disease.

The electrocardiographic findings of decreased Rwave amplitude suppression, first-degree atrium-ventricular blocks, multiform premature ventricular complexes, and ventricular tachycardia episodes were similar to the ones observed in dogs by Barr et al. [16], Andrade et al. [17], and Camacho et al. [18], and in humans by Brener et al. [19], Brenière et al. [20], and Punukollu et al. [21]. The abrupt cardiac deviation to the left, however, was consistent to the observations by Lana et al. [22].

The presence of first-degree atrium-ventricular blocks indicates degenerative alterations in the conduction system, especially in the region of the atrium-ventricular knot and associated conduction tissue $[7,16]$. From the literature consulted, only Pinto Dias [23] made references to the appearance of electric alternans episodes of the QRS complexes in carriers of Chagas disease, but it is known that this finding is related to myocardial inflammation and according to Tilley et al. [7] is related to the principle of right congestive insufficiency with pericardial effusion or pleural effusion.

Bradycardia episodes and second-degree atrium-ventricular blocks were not observed, as described by Andrade et al. [17] and Barr et al. [16], respectively.

Dynamic electrocardiography (Holter system) is very important in epidemiologic studies on sudden death, because it is the more accurate available method to detect symptomatic and asymptomatic arrhythmias [24]. In this study, dogs whose resting electrocardiographic test revealed more serious tachyarrhythmias had sudden death from the third week on. According to Rassi Jr. et al. [25], the trigger to malignant arrhythmias and sudden death may be the serious harm to the control of coronary microcirculation.

Similar to the dogs in this protocol, in chagasic human patients the incidence and prevalence of ventricular arrhythmias, especially episodes of sustained ventricular tachycardia, increase as the ventricular disfunction progresses [26].

Myocytes cultivation has demonstrated that the presence of amastigotes in myocardial cells determines the decrease in conduction and in cellular connection, impairing the electric impulse transmission, what might generate atriumventricular blocks and ventricular extrasystoles [26]. The occurrence of sudden death cases in this research coincided with the parasitemic peak, the amount of tachyarrhythmias observed at the Holter test. The theories presented by these authors state our conclusions about the sudden death in evaluated dogs.

According to Germiniani [24], the R-on-T phenomenon is frequently observed as a trigger of ventricular tachycardias and fibrillation. This claim confirms the observation of the Holter tracing of one dog from Group CA which died suddenly during dynamic electrocardiography evaluation, allowing, thus, the observation of such phenomena mentioned by this author.

In the chronic phase, resting and dynamic electrocardiographic evaluations allowed the observation of the remaining presence of these events in this phase of the infection, despite the evident decrease in the frequency of arrhythmic events, differing from what was found by KLEIN [11], at the evaluation of dogs inoculated with T. cruzi, Colombian strain.

The presence of decrease of R-wave amplitude, right branch block and arrhythmic events such as first-degree atrium-ventricular blocks and multiform ventricular extrasystoles corroborate the findings described by Lana et al. [22] and Carod-Artal et al. [27]. Furthermore, according to Germiniani [24], ventricular extrasystole constitutes the most frequent arrhythmia in chronic chagasic cardiopathy and it may be monomorphic or polymorphic, isolated, paired, or 
paroxysmal. According to Rassi Jr. et al. [25], the evaluation of the presence of this arrhythmia constitutes an important factor of prognosis and risk stratification for the patient.

Considering these results, it was possible to conclude that the experimental infection of adult dogs with Trypanosoma cruzi, Bolivian strain, using inoculum of 6000 trypomastigotes $/ \mathrm{kg}$, intravenously, allowed the obtainment of acute and chronic phase of Chagas disease, with parasitemic period from the 19th to the 33rd days after incubation and peak observed between the 21st and the 28th days, period with higher occurrence of sudden death. Therefore, this strain presented a later and longer parasitemic period than the others.

Moreover, computerized and dynamic (Holter system) electrocardiography allowed to diagnose transient arrhythmias efficiently and to observe that the main tachyarrhythmic alterations are concentrated in acute phase, concomitantly to the parasitemia peak.

Finally, the present study contributed to the supply of information on Chagas disease in dogs, promoting the detailing of its physiopathogeny.

\section{Acknowledgments}

The authors acknowledge FAPESP for the financial support to carry out this research; Capes for the grant offered; $\mathrm{CNPq}$ for the financial support; Professor Rosângela Zacarias Machado-Immunoparasitology_FCAV/UNESP; Professor Sérgio de Albuquerque-USP/Ribeirão Preto; Dr. Adalberto Menezes Lorga-Cardiovascular Diseases InstituteSão José do Rio Preto/SP.

\section{References}

[1] J. A. Marin-Neto, C. Bern, S. P. Montgomery et al., "Evaluation and treatment of chagas disease in the United States: a systematic review," Journal of the American Medical Association, vol. 298, no. 18, pp. 2171-2181, 2007.

[2] World Health Organization, "Division of Control of Tropical diseases, Elimination of Chagas disease as a Public Health Problem," Projected costs 1997-2010, Geneva, CTD/TRY/ 97.14 p. 41.

[3] S. P. Pavarini, E. C. Oliveira, P. M. Bandarra et al., "Miocardite chagásica em caninos no Estado do Rio Grande do Sul," Ciencia Rural, vol. 39, no. 4, pp. 1243-1247, 2009.

[4] J. P. Pascon, G. B. Pereira Neto, M. G. Sousa, D. Paulino Júnior, and A. A. Camacho, "Clinical characterization of chronic chagasic cardiomyopathy in dogs," Pesquisa Veterinária Brasileira, vol. 30, no. 2, pp. 115-120, 2010.

[5] Z. Brener, "Therapeutic activity and criterion of cure on mice experimentally infected with Trypanosoma cruzi," Revista do Instituto de Medicina Tropical de São Paulo, vol. 4, no. 6, pp. 389-396, 1962.

[6] M. E. Camargo, Introdução às Técnicas de Imunofluorescência, Instituto de Medicina Tropical, São Paulo, Brazil, 1973.

[7] L. P. Tilley, Essentials of Canine and Feline Electrocardiography, Lea \& Febiger, Philadelphia, Pa, USA, 3rd edition, 1992.

[8] R. Wolf, A. A. Camacho, and R. C. A. Souza, "Eletrocardiografia computadorizada em cães," Arquivo Brasileiro de Medicina Veterinária e Zootecnia, vol. 52, no. 6, pp. 610-615, 2000.
[9] G. W. Snedecor and W. G. Cochran, Statistical Methods, Iowa State University Press, Ames, Iowa, USA, 1980.

[10] I. B. M. Sampaio, Estatística Aplicada a Experimentação, FEPMVZ, Belo Horizonte, Brazil, 1998.

[11] R. P. Klein, "Avaliação clínica e contagem neuronal em gânglios nervosos cardíacos em cães experimentalmente infectados com Trypanosoma cruzi," in Dissertação (Mestrado em Medicina Veterinária), Faculdade de Ciências Agrárias e Veterinárias, Universidade Estadual Paulista, Jaboticabal, Brazil, 1995.

[12] S. C. Barr, K. A. Gossett, and T. R. Klei, "Clinical, clinicopathologic, and parasitologic observations of trypanosomiasis in dogs infected with North American Trypanosoma cruzi isolates," American Journal of Veterinary Research, vol. 52, no. 6, pp. 954-960, 1991.

[13] P. Penin, C. Gamallo, and J. A. De Diego, "Biological comparison between three clones of Trypanosoma cruzi and the strain of origin (Bolivia) with reference to clonal evolution studies," Memórias do Instituto Oswaldo Cruz, vol. 91, no. 3, pp. 285-291, 1996.

[14] E. S. G. Lopes and J. C. P. Júnior, "A influência da cepa y de Trypanosoma cruzi no coração em ratos wistar machos submetidos ao processo de adrenalectomia," Biodiversidade, vol. 6, no. 1, pp. 62-76, 2007.

[15] A. Y. N. Pinto, S. A. Valente, V. C. Valente, A. G. F. Junior, and J. R. Coura, "Fase aguda da doença de Chagas na Amazônia Brasileira. Estudo de 233 casos do Pará, amapá e maranhão observados entre 1988 e 2005," Revista da Sociedade Brasileira de Medicina Tropical, vol. 41, no. 6, pp. 602-614, 2008.

[16] S. C. Barr, R. A. Holmes, and T. R. Klei, "Electrocardiographic and echocardiographic features of trypanosomiasis in dogs inoculated with North American Trypanosoma cruzi isolates," American Journal of Veterinary Research, vol. 53, no. 4, pp. 521-527, 1992.

[17] Z. A. Andrade, S. G. Andrade, M. Sadigursky, R. J. Wenthold, S. L. Hilbert, and V. J. Ferrans, "The indeterminate phase of Chagas' disease: ultrastructural characterization of cardiac changes in the canine model," American Journal of Tropical Medicine and Hygiene, vol. 57, no. 3, pp. 328-336, 1997.

[18] A. A. Camacho, M. S. S. Teixeira, and R. Oliveira Alves, "Electrocardiography in adult dogs infected with Trypanosoma cruzi during acute and chronic phases," Ars Veterinaria, vol. 16, no. 3, pp. 158-164, 2000.

[19] Z. Brener and Z. A. Andrade, Trypanosoma cruzi e Doença de Chagas, 2nd edition, 2000, Edited by G. Koogan.

[20] S. F. Brenière, M. F. Bosseno, and F. Noireau, "Integrate study of a Bolivian population infected by Trypanosoma cruzi, the agent of Chagas disease," Memórias do Instituto Oswaldo Cruz, vol. 97, no. 3, pp. 289-295, 2002.

[21] G. Punukollu, R. M. Gowda, I. A. Khan, V. S. Navarro, and B. C. Vasavada, "Clinical aspects of the Chagas' heart disease," International Journal of Cardiology, vol. 115, no. 3, pp. 279-283, 2007.

[22] M. Lana, E. Chiari, and W. L. Tafuri, "Experimental Chagas' disease in dogs," Memórias do Instituto Oswaldo Cruz, vol. 87, no. 1, pp. 59-71, 1992.

[23] J. C. Pinto Dias, "Notas sobre o Trypanosoma cruzi e suas características bioecológicas, como agente de enfermidades transmitidas por alimentos," Revista da Sociedade Brasileira de Medicina Tropical, vol. 34, no. 4, pp. 370-375, 2006.

[24] H. Germiniani, Diagnóstico e terapêutica das arritmias cardíacas, Rio de Janeiro, Brazil, 3rd edition, 1990, Edited by G. Koogan. 
[25] A. Rassi Jr., A. Rassi, and J. A. Marin-Neto, "Chagas disease," The Lancet, vol. 375, no. 9723, pp. 1388-1402, 2010.

[26] A. A. J. Fuenmayor and P. A. M. Fuenmayor, "Muerte subita en pacientes com miocarditis chagásica," Archivos del Instituto de Cardiología de México, vol. 66, no. 2, pp. 157-161, 1996.

[27] F. J. Carod-Artal, A. P. Melo, and T. A. Horan, "American trypanosomiasis (Chagas' disease): an unrecognised cause of stroke," Journal of Neurology Neurosurgery and Psychiatry, vol. 74, no. 4, pp. 516-518, 2003. 


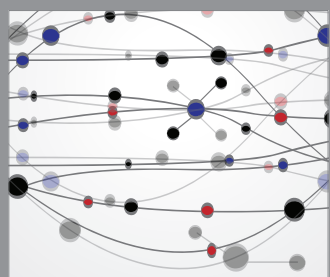

The Scientific World Journal
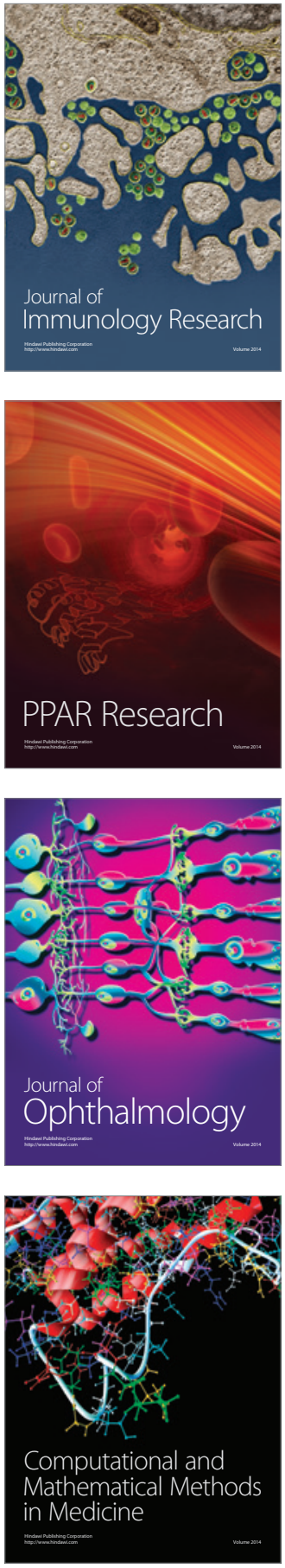

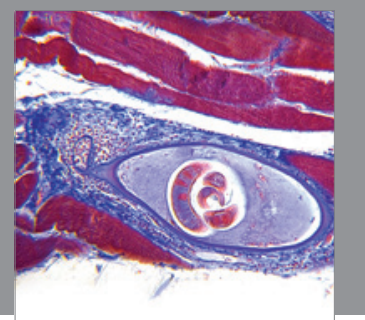

Gastroenterology

Research and Practice
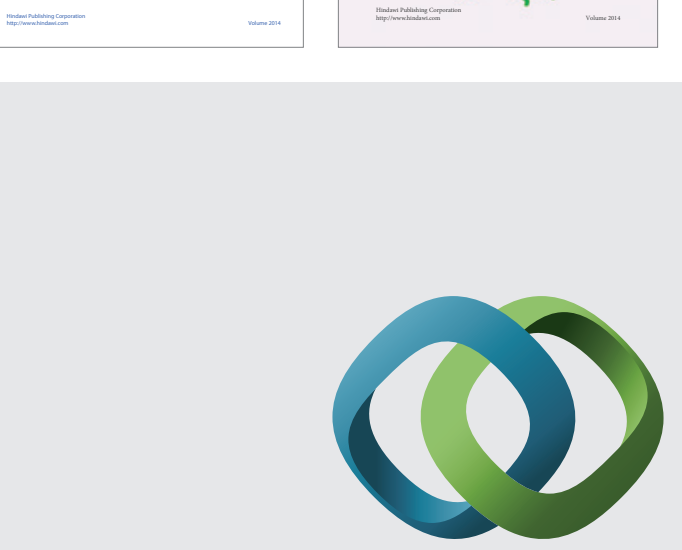

\section{Hindawi}

Submit your manuscripts at

http://www.hindawi.com
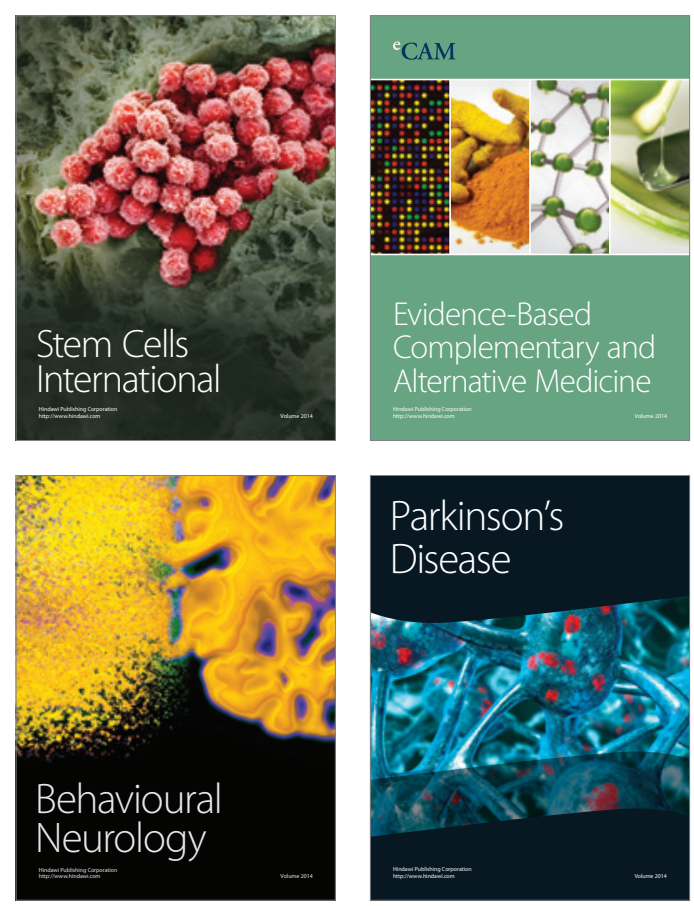

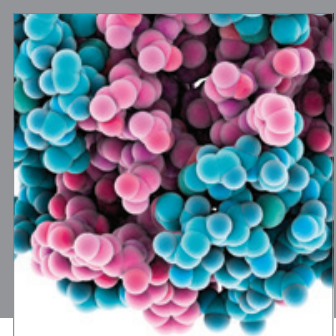

Journal of
Diabetes Research

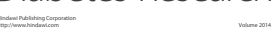

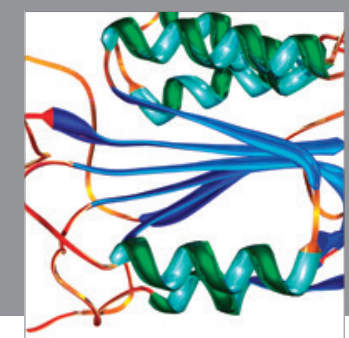

Disease Markers
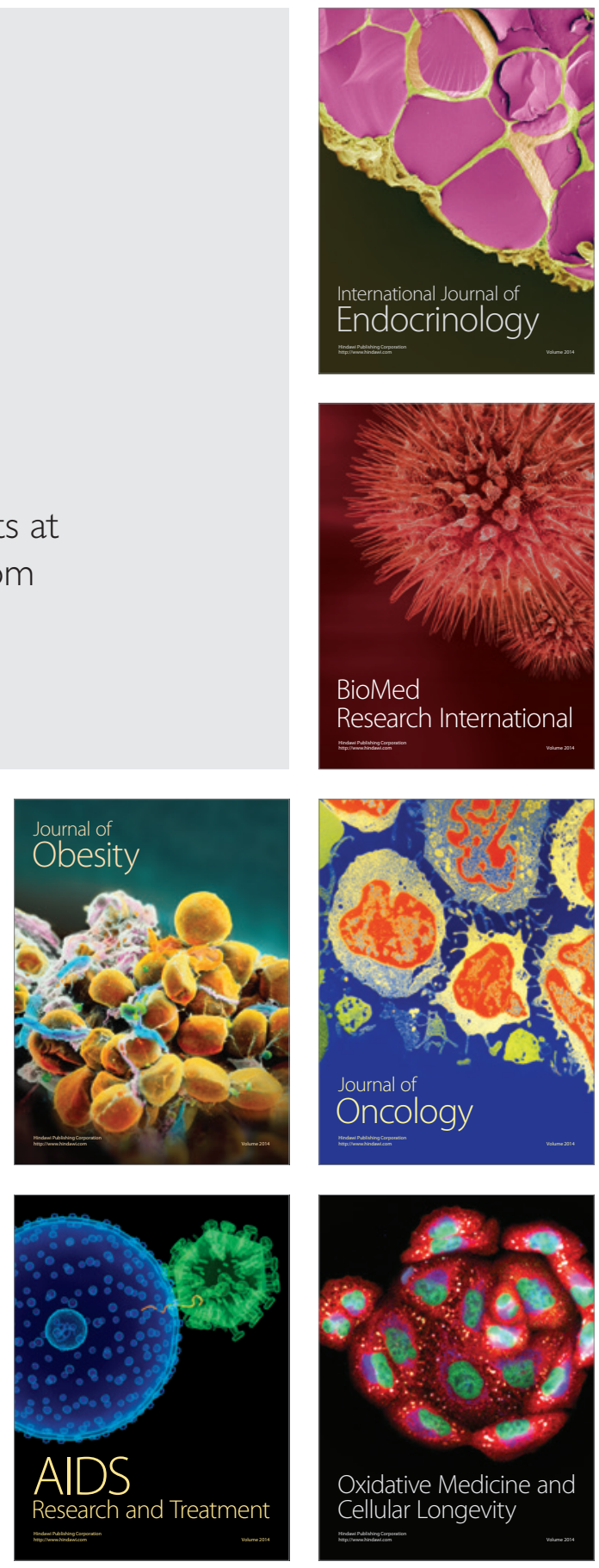